\title{
WORKING WITH LATINO STUDENTS IN RECOVERY: UNDERSTANDING CULTURE AND THE ROLE OF FAMILY
}

\author{
KRISTINA M. CANFIELD*
}

*KMC211@UAB.EDU; THE UNIVERSITY OF ALABAMA AT BIRMINGHAM WELLNESS PROMOTION LRC 3 RD FLOOR 17202 ND AVE S BIRMINGHAM, AL 35294

To cite this article: Canfield, K. M. (2018). Working with Latino Students in Recovery: Understanding Culture and the Role of Family. Journal of Recovery Science, 1(2), c7. https://doi.org/10.31886/jors.12.2018.22

To link to this article: https://doi.org/10.31886/jors.12.2018.22

\section{ABSTRACT}

This presentation explores and reflects upon the presenter's experiences after moving and adjusting to a new culture at a large university in deep-south Texas, on the US/Mexico border, and how those experiences align with current research available regarding cultural considerations in a therapeutic environment. The presentation reviews several case studies and their relationship to six important cultural considerations when working with Hispanic or Latino students. The presentation also explores the important role families play in the recovery process for Latino students involved in Collegiate Recovery Programs and recommendations for CRPs to assist in the involvement of families in programming. Attendees will learn how the presenter learned the importance of understanding the vital role culture plays in different recovery communities and how that affects students in or seeking recovery.

\section{EATING DISORDER RECOVERY: FOSTERING AN INCLUSIVE CULTURE}

\author{
EMMY L. HENLEY*, DIANA L. MONSOUR \\ *EMMY.LU.HENLEY@TTU.EDU; TEXAS TECH UNIVERSITY CENTER FOR COLLEGIATE RECOVERY COMMUNITIES \\ BOX 41160 LUBBOCK, TEXAS 79409 \\ To cite this article: Henley, E. L. \& Monsour, D. L. (2018). Eating Disorder Recovery: Fostering an Inclusive Culture. Journal of Recovery Sci- \\ ence, 1(2), c7. https://doi.org/10.31886/jors.12.2018.23
}

To link to this article: https://doi.org/10.31886/jors.12.2018.23

\section{ABSTRACT}

Eating disorder (ED) recovery is often difficult to define, which may leave those offering recovery support feeling lost and discouraged when determining ED services in their Collegiate Recovery Program (CRP). Although CRPs primarily support substance use disorders (SUD), research demonstrates $35 \%$ with a SUD recovery report also having an ED, thus making it imperative that CRPs understand and consider means for an ED supportive culture. Providing information to staff of CRPs on the state of ED recovery research and how to incorporate strategies for support, despite the size, tenure, or financial status of a CRP, is important for inclusion. Texas Tech offered their experience in their CRP and the evolution of ED support and culture within.

All authors approve this manuscript and the original submission. The authors report no conflicts of interest. This work is licensed under the CC-BY license. 